\title{
A Research Institute for Noble Metals
}

\section{THE WORK OF THE FORSCHUNGSINSTITUT FÜR EDELMETALLE}

In the eity of Schwäbisch Gmünd in Baden-Württemberg in the South of Germany a research institute, the only one of its kind in the world, has for over fifty years devoted itself to investigations in the metallurgy and chemistry of gold and the other noble metals and their alloys. This review marks the 70th birthday of its distinguished Director for many years, Dr Ernst Raub.

In 1921 a joint initiative by three interested groups, the city of Schwäbisch Gmünd, the state of Württemberg and the industrial companies engaged in the refining and fabrication of the noble metals in Germany, led to the foundation of a research organisation uniquely associated with these metals. Initially its mandate included research in metallurgy, more particularly of the noble metals, a duty to act as an independent assayer, and the establishment of training courses for the industry.

The city of Schwäbisch Gmünd, some 50 kilometres east of Stuttgart, was chosen as the home of the Institute primarily because it was one of the three German locations of the noble metals industry, the others being Hanau and Pforzheim, and secondly because there already existed in the town a training school for craftsmen, the Staatliche Höhere Fachschule für die Edelmetallindustrie, which could house the newly formed institute and in which members of its staff could take part in teaching.

The first three directors of the Institute in its early years were Dr Rudolf Vogel from the University of Göttingen, then Dr Hans Moser, the director of the State Mint at Stuttgart, and later Dr J. A. A. Leroux.

In 1928 a young metallurgist who had just obtained his $\mathrm{Ph} . \mathrm{D}$ at the University of Münster joined the Institute as a research associate; six years later he was appointed its Director and his association with the Institute continues to this day. This was of course Dr Ernst Raub, who has an exceptionally wide international reputation in his field.

The centre of the town of Schwähisch Gmünd in South Germany has a delightfully medieval appearance, but not far from this is the modern building of the Forschungsinstitut, devoted to research on gold and the other noble metals and their alloys
Under Dr Raub's direction the great contributions to the physical metallurgy of gold and the other noble metals began, and the first of a long series of investigations of the equilibrium diagrams of gold alloys was published in 1933. Since that time some twenty-seven systematic studies of the constitution of gold alloys have been published, including those of binary gold alloys with the transition elements of Groups IV, V, VI, VII and VIII of the Periodic Table. In addition a number of investigations have been completed on ternary gold-copper alloys with silver, nickel, palladium, zinc and cadmium, and of other ternary alloys such as gold-nickel-palladium

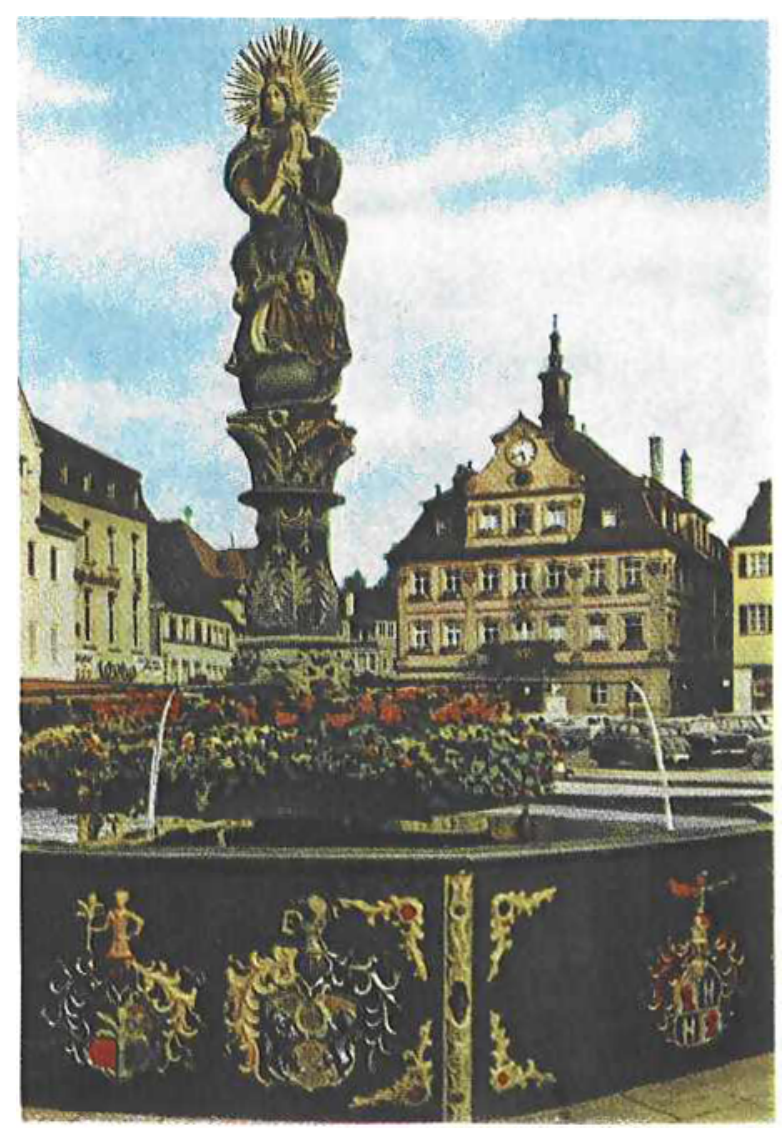




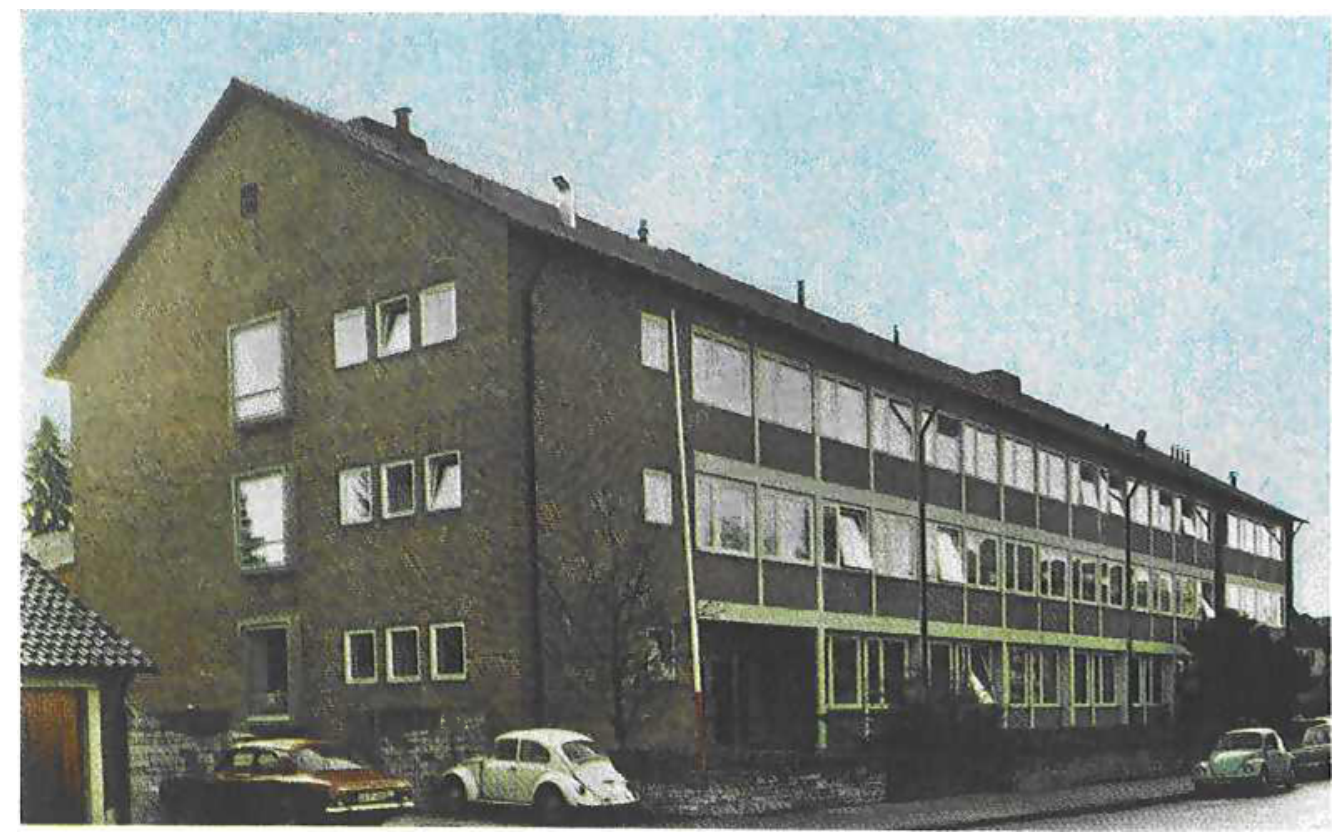

The present laboratories of the Forschungsinstitut were erected in 1959 to replace older and smaller premises which the Institute had outgrown. They are well equipped for research in the metallurgy and metal physics of the noble metals and for investigations in electrochemistry

and gold-platinum-rhodium. As long ago as 1940 Dr Raub published his book on noble metal alloys, "Die Edelmetalle und ihre Legierungen", the first work of its kind on this subject, and he has in all published over 300 papers.

Further studies have been made on the structure and constitution of a number of binary gold alloys prepared by electrodeposition, including those with copper, silver, lead, antimony, zinc, cadmium and

\section{Dr Ernst Raub}

On his 70th birthday on April 5th Dr Raub can look back with great satisfaction on forty-seven years of association with the Forschungsinstitut, first as a young research worker, for thirty-six years as its Director, and since 1970 as its senior consultant and adviser to his son and successor, Dr Christoph Raub. The long series of researches on the constitution of gold alloys and on the electrodeposition of gold and its alloys carried out under his inspiration and leadership have earned him a high international reputation, while under his leadership the Institute has grown from its modest status forty years ago to an important and well recognised research centre. The most recent of his many honours was the 1974. Scientific Achievement Award of the American Electroplaters' Society bismuth. Electrodeposition and the structure of electrodeposited metals and alloys have in fact become major features of the Institute's work, and this development led to a change of the Institute's name in 1957 to the Forschungsinstitut für Edelmetalle und Metallchemie.

The major contribution from Dr Raub and his associates in this field has been the basic study of the mechanism of deposition of both metals and alloys,

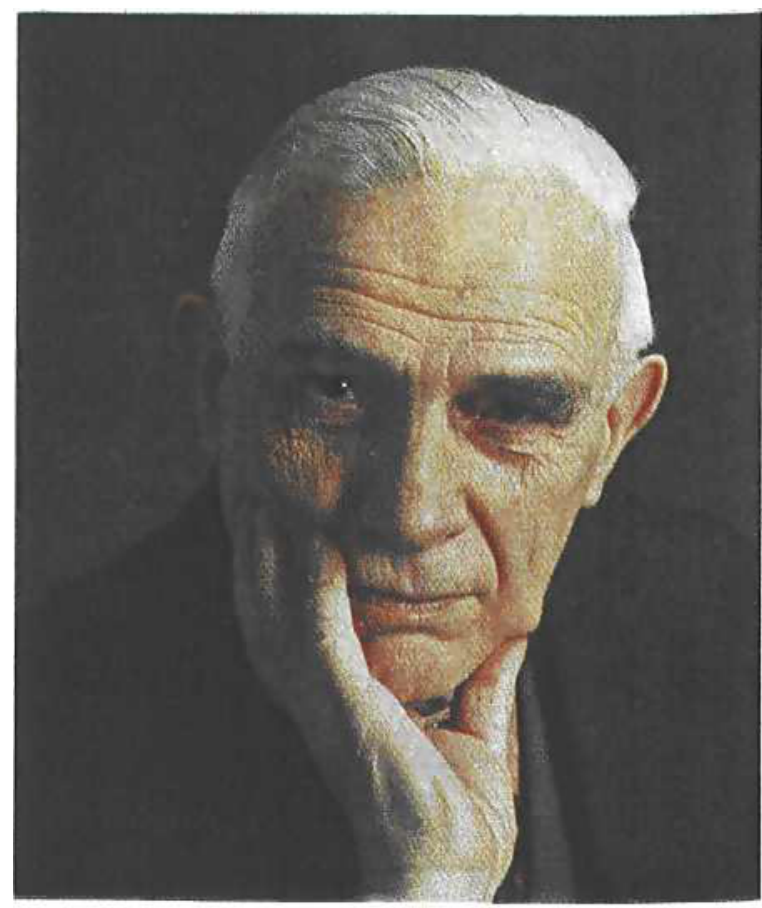




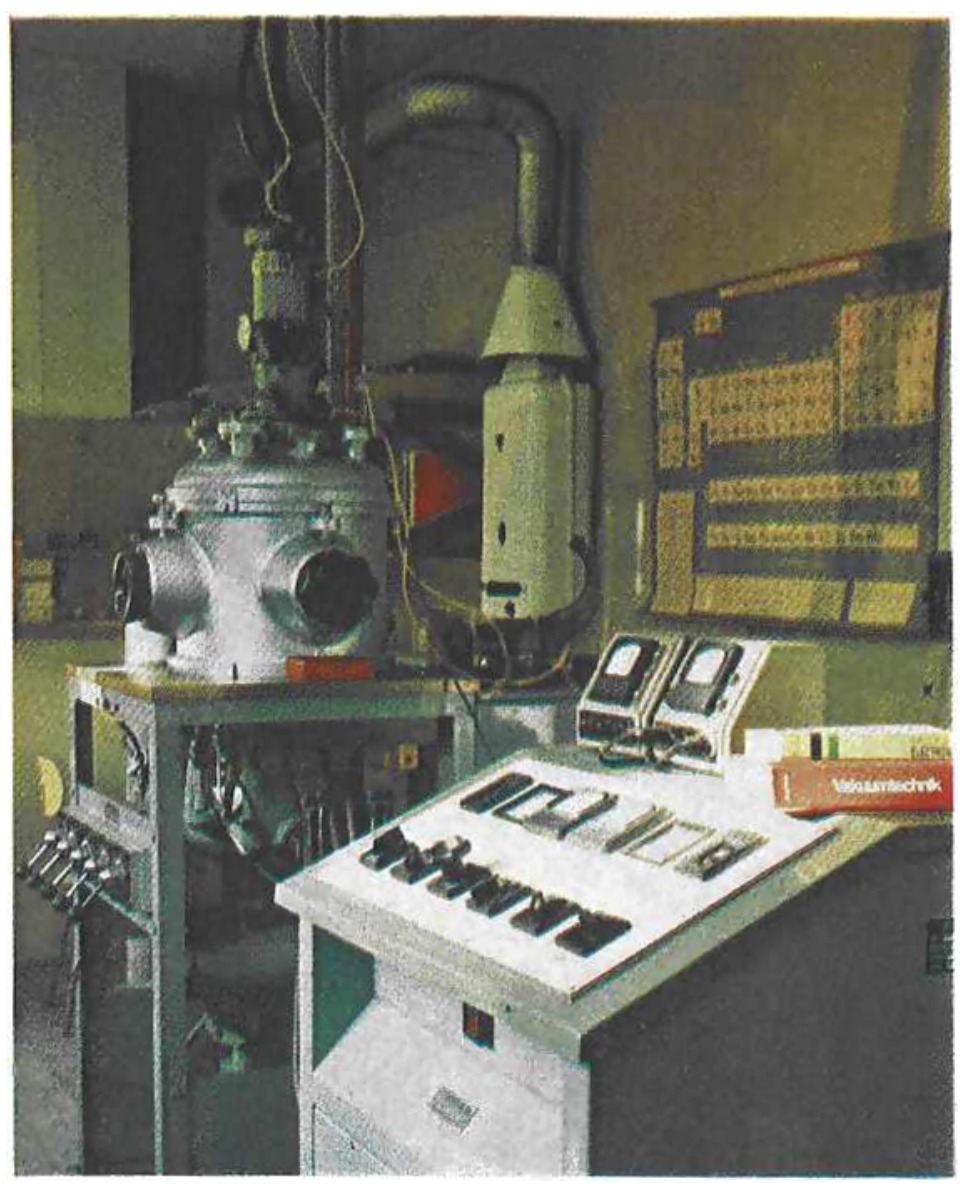

Among the range of melting units available is this argon are furnace for melting and casting gold and other noble metal alloys on a semi-commercial scale. The development of new or improved gold alloys has been a characteristic feature of the Institute's work over the past fifty years

investigated from the scientific angle, industrial applications have always been well in mind; this work resulted in 1958 in the development of an acid gold plating electrolyte based on boric acid, and later of a successful goldcopper-cadmium electrolyte. Further work has been carried out on the micro-throwing power of gold electrolytes in which relationships were established between the mechanism of deposition and polarisation processes and the levelling of deposits, while work is continuing on the problem of the co-deposition of organic polymers in gold plating and its effects

using both current density-electrode potential curves and metallographic examination as the means of investigation. The constitution and structure of electrodeposited alloys were found to differ considerably from those associated with the same series of alloys in wrought form, and important relationships were established between the electrochemical processes involved and the structure and properties of the deposits.

To give only one example, it was found that while electrodeposited gold-silver alloys form a continuous series of solid solutions, gold-copper alloys from alkaline cyanide solutions behaved quite differently; although these also form a continuous series of solid solutions from the molten state, when electrodeposited they crystallise independently. This finding was of considerable practical importance in explaining the poor resistance to corrosion of electrodeposited gold-copper alloys compared with the high resistance of gold-silver alloy deposits.

The whole complex problem of the electrodeposition of alloys-its economic advantages often outweighed by the sensitivity of composition to electrochemical factors-has in fact been elucidated to a great extent by the work of Dr Raub and his associates.

While the electrodeposition of gold alloys has been on the properties of the deposits. The mechanical properties of gold deposits have also been investigated, and a method of assessing internal stress in deposits has been developed.

Research has not been confined, however, to electrodeposited gold, but has extended to studies of sputtered, evaporated and clad gold coatings and their comparative properties and usefulness.

The laboratories of the Institute are well equipped for investigations in metallurgy and electrochemistry. Melting can be carried out in a range of induction, arc and electron beam furnaces, while annealing and heat treatment furnaces are installed for temperatures up to $2000^{\circ} \mathrm{C}$. Small scale rolling, swaging and wire drawing equipment is available, while $\mathrm{X}$-ray diffraction, electron diffraction, and electron microscopy and interferometry can be called upon as well as a magnetic balance for solid state investigations. Equipment for studies on superconductivity is also in use down to a temperature of $2^{\circ} \mathrm{K}$. Equipment in the electrochemical section includes rotating ring disc electrodes, potentiostats, galvanostats and other electronic instruments, and means of measuring the thickness of electrodeposits include eddy current, beta back-scatter and coulometry. Absorption measurements can be made on spectrometers sensitive from the infra-red to the ultra-violet range. 
One of the subjects of current interest is research on the superconductivity of gold alloys and intermetallic compounds. This equipment is for the measurement of superconductivity at temperatures down to below $2^{\circ} \mathrm{K}$

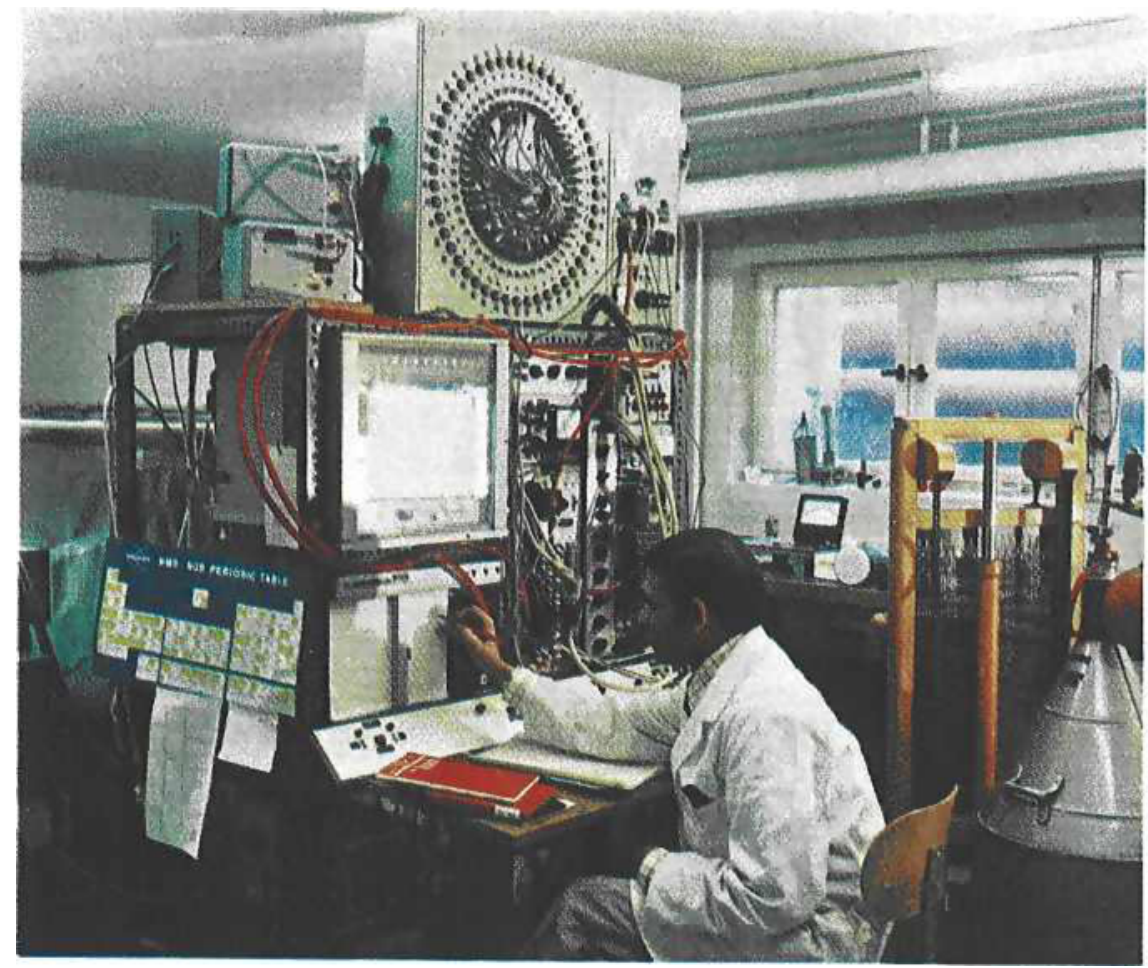

The Institute carries out both basic research supported by government departments and specialised contract research funded by national and international companies, such as investigations on the development of new electrical contact materials and their performance in service. Collaboration with industry has been most successful, and there are many products now on the market in the noble metals field in which the Institute has played a decisive role in their development. Its unique character has also led to the establishment of valuable connections with both industry and the universities throughout the world, and visiting scientists who have recently spent a working period in the laboratories include metallurgists, chemists and physicists from the U.S.A.,
Great Britain, Japan, Hungary, Norway, Poland, and India.

In 1970 Dr Ernst Raub retired as Director of the Institute and was succeeded by his son, Dr Christoph Raub, under whose enthusiastic guidance work on the metallurgy and metal physics of the noble metals and on their electrochemisty continues.

This is the only independent research organisation in the world specialising in the noble metals, and one of the few devoted to research in electrodeposition. Now in its sixth decade, it can be expected that many more contributions to the understanding and use of gold and its alloys will emerge from the Institute's work in the years to come.

L. B. H.

$\mathrm{T}$ HE most perfect of all Inanimate bodies, and the most esteemed of all Mettals is Gold, universally known, and coveted by all people. It is made of the same matter, and in the same manner as other Mettals are, but of parts so pure and perfect, and so well compacted together by decoction, that its substance is, as it were, incorruptible, being out of the power of any of the Elements to be corrupted or destroyed. The fire that consumes all other Mettals only makes Gold more pure. The air and water diminish not its lustre, nor can Earth make it rust or waste.

From the translation by

Edward Montagu, Earl of Sandwich

ALVARO ALONSO BARBA

London, 1669

El Arte de los Metales

Madrid, I640 